\title{
Borrego Gutiérrez, Esther; Marín López, Javier (eds.), El villancico en la encrucijada: nuevas perspectivas en torno a un género literario-musical (siglos XV-XIX), Kassel, Edition Reichenberger, 2019, 627 pp.
}

La serie Iberian Early Music Studies de la editorial Reichenberger acaba de publicar su tercer volumen, dedicado al villancico entre los siglos XV y XIX. Los coordinadores no podían ser más idóneos para cubrir un género tan proteico y difundido en las literaturas hispánicas: Esther Borrego Gutiérrez, de la Universidad Complutense de Madrid, y Javier Marín López, de la Universidad de Jaén. Y decimos que son los más idóneos porque sus trayectorias así lo ratifican. Por un lado, la profesora Borrego Gutiérrez nos viene brindando desde hace casi una década magníficos estudios en torno al tema, con un enfoque filológico y frecuentemente dentro de un paisaje madrileño: «Los autores de las letras de los villancicos de la Capilla Real de Madrid (siglo XVIII)», «Un siglo de impresión de pliegos de villancicos. El caso de los Monasterios Reales de la Encarnación y las Descalzas (1649-1752)», o «Entre burlas y veras: villancicos barrocos cómicos para el niño Jesús», además de haber dirigido la tesis doctoral El villancico en la Real Capilla de Madrid en el siglo XVII: dimensión genérica, espectacular y social, de Eva Llergo Ojalvo, autora presente en el volumen. Por su parte, la carrera del profesor Marín López se vertebra en decenas de títulos consagrados a la música antigua a uno y otro lado del Atlántico, con especial atención al contexto catedralicio mexicano: «The musical inventory of Mexico Cathedral, 1589: a lost document rediscovered», «Cazadorcito se ha hecho el amor de Gregorio Portero (1733), o de la diáspora de un villancico granadino a Nueva España», o mediante los volúmenes consagrados a la figura del maestro Ignacio Jerusalem (1707-1769). Actualmente, el estudioso giennense es, además, director de la prestigiosa Revista de Musicología y del Festival de Música Antigua de Úbeda y Baeza. Con tales curricula el lector tiene todas las garantías de que la «encrucijada» en la que se nos emplaza el villancico va a ser representada y aun reivindicada con éxito. Es en ese cruce de caminos donde reside, precisamente, la principal aportación de la miscelánea: en la combinación y superación de los análisis que dan cuenta de la dimensión poética y musical del fenómeno (sin olvidar la sociológica o la crítica), y en la apertura del foco geográfico hasta el mundo novohispano, escapando del pesado eurocentrismo. Añadido a esto, el libro pretende «ofrecer un balance crítico de la investigación reciente y, al mismo tiempo, generar un nuevo marco de referencia para futuros trabajos centrados en el que, sin lugar a dudas, es uno de los más ricos y fascinantes patrimonios culturales del mundo hispánico» (pp. XVII-XVIII), en palabras de los dos investigadores. El primer objetivo se vislumbra ya desde la presentación liminar, en la que se constata el interés de la crítica por el villancico en los últimos años: quince tesis doctorales desde 2009, seis antologías 
musicales desde 2011, tres grandes catálogos de pliegos desde 2000, y la obra que ahora reseñamos, segundo volumen colectivo sobre el género tras el magno Devotional Music in the Iberian World, 1450-1800. The Villancico and Related Genres (2007), coordinado por Tess Knighton y Álvaro Torrente. Eso sin contar con los proyectos de investigación que han hecho posible la aparición de esta obra: Catálogo descriptivo de pliegos de villancicos, fase 5, del entonces Ministerio de Ciencia e Innovación, y Espacios, géneros $y$ públicos de la música en Madrid, siglos XVII-XX, de la Comunidad de Madrid. El segundo objetivo, el de la referencialidad, vendrá rodado por la calidad de sus páginas, según iremos viendo a continuación.

Para alcanzar dichas metas y enfatizar el valor de la propuesta, las veintidós contribuciones se han distribuido en una introducción y cinco apartados que delimitan y señalan los contenidos: el primero trata sobre la conformación y evolución del género; el segundo, el villancico en tanto código privilegiado de comunicación social; el tercero, el contexto catedralicio; el cuarto, contextos alternativos al eclesiástico; y el quinto, una serie de análisis poético-musicales de composiciones específicas. Haremos algunas calas en cada sección de modo que tengamos un panorama equilibrado del conjunto sin redundar en los resúmenes que, con buen criterio, se han incluido junto con los índices finales.

La introducción corre a cargo de Andrea Bombi, quien acomete un magistral estado de la cuestión en «¿Hacia una historia del villancico? Problemas historiográficos de un género musical». Para el autor, fue el congreso Secular Genres in Sacred Contexts? The Villancico and Cantata in the Iberian World, 1400-1800, celebrado en Londres en 1998, el que marcó un punto de ruptura en la bibliografía crítica sobre el género, superándose las propuestas de Mitjana (1920), Ripollés (1935), Subirá (1953), Rubio (1979), LópezCalo (1983), o Laird (1997). A partir del evento de 1998 se hizo necesaria la distinción metodológica entre las formas musicales del villancico y sus funciones, dos caras que respondían a incógnitas en torno a los cambios formales adoptados y la finalidad de una canción en romance en la liturgia. Respecto del primer punto, el investigador subraya la relación entre institucionalización y un villancico policoral articulado en (introducción)estribillo-coplas, o la existente entre los elementos de la cantata de cámara y las formas «recitado» y «aria» como miembros constitutivos del villancico entre 1670 y 1730. Respecto del segundo, es clave la sociología literaria de Ruiz Pérez. Sus tesis ayudan a Bombi a enfatizar que el villancico, al dirigirse a un público heterogéneo y estratificado, favorecía cierta cohesión social. Podría ser un recurso para garantizar mayor visibilidad de los laicos en el universo festivo, pero también para «satisfacer las expectativas de todos los componentes del público», crear una identidad, o mediar en las tensiones connaturales del campo literario. Al abordar el villancico como género musical ya desde el título, la profunda revisión de Bombi se escora principalmente hacia el plano performativo del fenómeno, echándose en falta una reflexión sobre su materialidad inmediata, si bien parcial: la dimensión editorial. La regularización de los rótulos, formatos, y otras señas identitarias del consumo literario del villancico contribuyó en la estabilidad de su estructura interna (a pesar de la variedad léxica de sus partes) y en la amplitud social de sus receptores. Creemos que la codificación emprendida por los agentes intermediarios merecería mayor atención en una historia del género, especialmente si se quiere redondear su proceso productivo y comunicativo. En tanto llega esa historia global y definitoria (nunca definitiva), Bombi acierta al evidenciar los escollos más relevantes que se deben sortear en investigaciones futuras.

Paradójicamente, en el apartado primero, nacimiento del volumen, nos hemos interesado por la crisis y muerte del villancico. Muerte que no parece tener un epitafio 
concluso, según nos previene Eva Llergo Ojalvo en «Siglo XIX: ¿el fin del villancico (paralitúrgico)?». La autora parte de la consabida idea de que «el siglo XIX supuso el golpe de gracia que acabó desterrando de iglesias y catedrales a ese género tan popular» para, a continuación, proponer su propio corpus de investigación con el que refrendarla o matizarla. Ese corpus está constituido por 76 pliegos de villancicos de la BNE, fechados entre 1800 y 1836 y procedentes de 21 localidades españolas. A partir de ahí, Llergo Ojalvo constata que la censura que coaccionó el villancico desde mediados del siglo XVIII produjo diferentes mecanismos para su regulación y supervivencia en los templos: desde la disminución de su cantidad hasta su mayor apego a los textos sagrados. En ese aspecto, sus conclusiones respaldan las motivaciones del declive aducidas por $\mathrm{M}^{\mathrm{a}}$ Pilar Alén (1990), aunque añaden una causa más: la pérdida de la teatralidad y el carácter popular, verdadero anzuelo con que se atraía a los fieles a la iglesia. El corpus, no obstante, proporciona nueva información sobre esa crisis del villancico decimonónico que induce la pregunta del título del capítulo. A pesar de que el género perdía fuerza en los espacios sagrados, este la iba ganando en contextos profanos y privados gracias a la impresión de pliegos de villancicos para cantar en la Navidad, los cuales seguían presentando su color de antaño y una funcionalidad similar a las «Coplas para cantar al tono de...» de finales del Quinientos. Estos novedosos pliegos «no están ya, pues, asociados a ninguna fecha o institución concretas, siendo útiles para la celebración de cualquier Navidad en cualquier ámbito, ya fuera religioso o profano». Pese a la originalidad e impacto de este fenómeno, la autora deja en el aire detalles de cronología: ¿hasta cuándo circularon esos villancicos navideños?, ¿murieron también en el XIX o se pueden rastrear bajo diferentes ropajes hasta la actualidad? Como se ve, incógnitas que hacen aún del villancico un género tremendamente atractivo.

Para el segundo apartado escogemos una propuesta que nos invita a viajar a la América novohispana: «Pliegos de villancicos conservados en bibliotecas mexicanas», de Anastasia Krutitskaya. Su investigación reúne un corpus de 141 [i.e. 143] pliegos conservados en siete fondos de México, tanto públicos (Biblioteca Nacional de México) como privados (biblioteca privada de Puebla). Del repertorio se extraen valiosísimas ideas en torno a la conservación de villancicos impresos en colecciones y otras misceláneas, y la utilidad de estos más allá de las coordenadas espaciotemporales para las que fueron compuestos. Así, por ejemplo, a lo largo de las descripciones que hace la autora, se atestigua el empleo de villancicos de la catedral de Sevilla en la liturgia del convento de la Merced (Puebla); la importancia del obispo Juan Palafox y Mendoza a la hora de instaurar fiestas para las que se escribieron los que parecen ser los primeros villancicos impresos en la Nueva España (1648-1652); o el impacto y éxito de los villancicos de sor Juana Inés de la Cruz, muchos de ellos con las anotaciones autógrafas de la poeta que en su día dio a conocer Menéndez Plancarte (1945). Dejando a un lado las obras de autor (León Marchante, Pérez de Montoro, etc.) que incluían villancicos, las colecciones de estos pliegos inventariados señalan que «se resguardaban para la lectura tanto en el siglo XVIII como en el XIX», que pudieron reimprimirse en contextos editoriales dispares de carácter teatral, que su difusión «no terminaba en la catedral ni se limitaba a su espacio» y que el coleccionismo los preservó para darles nueva vida desde la lectura.

Sin movernos de México, en el tercer apartado Javier Marín López nos brinda algunas ideas sobre «El villancico religioso en la Puebla de entre siglos (XVII-XVIII): algunas consideraciones litúrgico-formales». El inventario de villancicos del 20 de junio de 1718, elaborado a instancias de varios cargos de la capilla musical de la catedral de Puebla, registra unas 2500 composiciones, según cálculos del autor. Carreras (1993) 
y Stanford (2001) dieron noticias del manuscrito junto con someras conclusiones que necesitan limarse, de ahí la necesidad de este examen, que explota por fin toda su información e implicaciones. Entre esos datos, se observa que el compositor más activo fue Miguel de Dallo (con unos cuarenta villancicos por año), que las advocaciones con mayor protagonismo fueron el Corpus, la Navidad y la Concepción (frente a festividades de larga tradición peninsular como la Adoración de los Reyes), y que la plantilla empleada para su ejecución muestra un predominio de las formaciones a cuatro y a dúo. En cuanto a la afirmación sostenida por Carreras de que el programa musical de la catedral de Puebla fue conservador, en base al viejo estilo en que se tejieron sus villancicos, Marín López expone sus reparos. Por un lado, advierte de que la incorporación de nuevos estilos en el vocabulario musical no siempre se aprecia en documentos como el que se estudia, y que la pérdida de las partituras nos priva igualmente de conocer ese proceso de transformación. Por otro lado, testimonios como los nombramientos de nuevos maestros reflejan un aggiornamento del villancico poblano rebasado el ecuador del XVIII, en paralelo al experimentado en capillas peninsulares y mexicanas (catedral de México y de Lima, por caso). Independientemente del cambio de estilo, parece claro que el villancico en la ciudad angelopolitana fue cuantitativa y creativamente significativo en estas fechas, lo que demuestra que Puebla fuera uno de los núcleos más influyentes y dinámicos de la época colonial.

A continuación, y adentrándonos en el cuarto apartado, reemplazamos el viaje espacial por el temporal, gracias a Víctor Infantes y su periplo por los albores del siglo XVI: «La cartografía poética (y narrativa) de un villancico tardomedieval: Abras me tú el hermitaño, sonar lírico en Navidad (con un prosímetro)». Desde las coplas de Enrique de Oliva, a través de la edición sevillana impresa por J. Cromberger entre 1505 y 1510 , la indicación de cantar un poema «al tono de Abras me tú el hermitaño» ha ido pasando de pliego en pliego (1516-18, 1535, 1568, 1603), de autor en autor (Cristóbal de Pedraza, Lope de Sosa) y de una a otra parte de la Península (Burgos, Granada, Cuenca) sin que conociéramos el desarrollo y tonada líricos ocultos tras ese primer verso aludido. Referencias a este contrafactum musical se leen también en antologías de tradición sefardí, como Sefer imré nó'am, de Jozeph Shalom ben Shalom Gallego (Amsterdam, 1628), por lo que es lícito pensar que fue ampliamente difundido y rápidamente reconocible para los lectores entonces. No obstante, en la bibliografía actual Abras me tú el hermitaño iba camino de ser un cadáver lírico del que solo se conservaba un miembro mútilo. Afortunadamente, el cuerpo textual perdido quedó transcrito en un pliego atribuido al taller sevillano de Cromberger entre 1506-1511, concretamente en un prosímetro al cierre del impreso bajo el título de «tratadillo». Si bien de su existencia ya dieron cuenta el propio autor y Askins en 2014, su relectura por parte de Infantes resuelve el enigma y nos devuelve un diálogo moral en el que las tentaciones y deleites de este mundo piden al virtuoso ermitaño un asilo del todo inviable.

En el quinto apartado tomamos el vuelo al completo, en cronología y localización geográfica, y nos plantamos en Santiago de Cuba a principios del siglo XIX. En «Villancicos tardíos en la catedral de Santiago de Cuba. Estética clásica, tópicos musicales y figuras retóricas en Oíd cielos piadosos (1809) de Juan Paris», Claudia Fallarero acomete un espléndido estudio armónico-formal de Oíd cielos piadosos, uno de los cincuenta y nueve villancicos autógrafos de Paris conservados en la catedral de Santiago de Cuba. En las diferentes partes y movimientos de la pieza, Fallarero cree ver al músico siguiendo las principales tendencias del lenguaje instrumental sinfónico de la estética clásico-vienesa. El rasgo clasicista se trasluce principalmente en la influencia del oratorio de Haydn 
(arranques de estribillos con líneas melódicas a solo, contrastes del cantabile de un solo de tiple con la declamación del coro, etc.), a la que se acoplan los modelos del oratorio de Queralt. Una muestra, en definitiva, de que Paris supo acomodar un discurso moderno con que darle algunos años más de vida al villancico dentro de la liturgia.

A excepción de Alfonso Colella, cuyo estudio está escrito en inglés, los autores hacen gala de un español ágil, pero profundo, cubriendo todos los frentes imaginables del mundo villanciqueril: cortes cronológicos, espacios, contextos, perspectivas de análisis, fuentes de estudio, etc. Características que hacen del libro un manual completo y accesible. Es cierto que algunos de los estudios musicológicos del quinto apartado requieren de una formación más específica de la que posee el que firma estas líneas, pero en cualquier caso son fáciles de leer y de seguir en sus argumentaciones. Como en cualquier manual que se precie, valoramos positivamente su bibliografía actualizada, con entradas hasta 2018, así como sus múltiples índices finales. Figuras, reproducciones de manuscritos, impresos, partituras, tablas, anexos con los corpora analizados... atraviesan la obra y la vuelven aún más didáctica. Tal es el despliegue gráfico que estos recursos disponen de un índice propio, el cual, en nuestra opinión, hubiera encajado mejor junto al resto de índices, para redirigir siempre al lector hacia esa sección última del volumen, en caso de consulta.

Por último, como asistente que fui del congreso internacional que dio origen a esta novedad editorial (Nuevas perspectivas en torno al villancico y géneros afines en el mundo ibérico: siglos $X V$-XIX, celebrado en Baeza entre el 2 y el 4 de diciembre de 2014) puedo certificar la excelencia de estos autores y sus estudios, los cuales, ya en su momento y de viva voz, dieron fe de que el villancico aún reserva un amplio corpus documental que rescatar y del que surgirán tantas y tan buenas sorpresas como estas que ahora se nos presentan.

Cipriano López Lorenzo

(Université de Neuchâtel, Suiza) 